supplied with a small outlet stack 20 feet high which is sufficient to compensate for the resistance offered to the gases by the treater. As stated above, sensitive pyrometers do not indicate any change of temperature in the kilns or stacks when the gases are permitted to escape directly into the atmosphere or are passed through the treater.

The operating costs of the apparatus are low. A complete treater of the size described consumes approximately $7^{\mathrm{I} / 2}$ kilowatt hours. This includes electrical energy for all motors. A 5,000 barrel mill will, therefore, consume approximately 75 kilowatt hours in an entire installation. The manual labor required consists of one man per shift, of the character of men ordinarily employed to run electrical mill machinery. It is, however, usually advisable to have an extra man on duty. There is no deterioration in the apparatus under steady running and the machinery is subject to exactly the same wear as any other piece of electrical machinery.

In the series of photographs shown, Fig. I shows the factory as it appeared in rgro with the experimental flue No. I and laboratory on the ground in front of the building. Fig. 2 gives a closer view and shows the initial experimental installation of two small precipitating units on the roof of the kiln room and just above the middle of the picture. The first full sized treater is at the right or opposite end of the row of stacks; Figs. 2 and 3 represent pictures taken I minute apart and show very plainly the effect of turning on the electrical current in the treater. In Fig. 3 the solid particles are all retained in the treater; the smoke from the other nine kilns is, of course, unaffected. Figs. 4 and 5 are views of experimental treaters built on the top of the stack. Fig. 6 is the first part of the permanent installation.

One important question which has grown out of the present work at the Riverside Portland Cement Company lies in the possible utilization of the collected material as a source of potash for fertilizer purposes. This factory does not use clay in its raw mix but a decomposing feldspar which has a considerable potash content. In the burning of the cement the potash is volatilized and condenses again in passing up the stack. The greater part is caught in the electrical treater along with the dust which gives a dust containing considerable potash value. Experiments have been conducted for some little time in the endeavor of utilizing this material either directly as a fertilizer "ffller" or extracting the potash from the material with the aim of obtaining a concentrated potash salt. This work is not sufficiently far advanced to permit publishing definite figures.

Dr. F. G. Cottrell, inventor of the process, is presenting a paper to this Congress before the Section of Conservation and Political Economy upon what he has termed "An Experiment in Public Administration of Patent Rights." This deals with the recently organized "Research Corporation" to which Dr. Cottrell and his associates have given the Patent Rights to the processes for all of the United States except the six western states and the application of the processes to the Portland cement industry. These latter rights, along with the foreign holdings, are retained by the parent companies, the Western Precipitation Company and the International Precipitation Company, with offices at Los Angeles, California.

Los ANgeles, California.

\section{CONTACT SULPHURIC ACID FROM BRIMSTONE.}

By G. W. Patterson and L. B. Cheney.

The plant we purpose to describe was erected in I907 at the U. S. Naval Proving Ground, Indian Head, Md., for the manufacture of acid used in making smokeless powder. It was designed by the New Jersey Zinc Co., which controls the Schroeder patents in this country.

With a rated capacity of six tons, it was operated successfully for three years, burning pyrites from New York and Virginia in O'Brien burners. During the last two years, Louisiana brimstone has been used entirely. The reason for changing raw materials was primarily to increase capacity without enlarging the plant, and it was hoped incidentally to reduce costs, notwithstanding the large increase in price per unit of sulphur. Our expectations have been fully realized in both respects.

The installation will be described under four heads: burner and gas cooling system, gas purifiers, conversion system, and absorbing system. The burner is housed in a detached frame building, I9 $\mathrm{ft}$. $\times 3^{2} \mathrm{ft}$., with sulphur store sheds adjacent. A frame building, $52 \mathrm{ft} . \times 60 \mathrm{ft}$., contains the conversion and absorbing systems. The gas cooling and purifying systems are in the open at the rear of the two buildings, in part protected by an open shed.

The burner is known as the Tromblee and Paull burner and has been most satisfactory. It consists of a horizontal cylindrical iron shell 8 feet long and 3 feet in diameter with conical ends, revolving on its axis once in two minutes. At one end is a hopper and worm feed with sliding dampers. The other end connects with a rectangular cast iron box of $37 \mathrm{cu}$. $\mathrm{ft}$. capacity, provided with sliding damper and vertical cast iron uptake pipe. This pipe leads to a brick dust catcher such as is ordinarily used with pyrites burners. The dust catcher merely cools the gas, as no appreciable amount of sulphur is carried beyond the combustion box.

The burner is rated at 5500 lbs. per day, but there has been no difficulty in burning 6000 lbs. per day. Before feeding to the hopper, the sulphur needs no other preparation than breaking up large lumps with a shovel. When forced along by the worm, the sulphur melts just before it drops into the body of the burner, and a sufficient amount of melted sulphur is always present to form a complete liquid coating on the inside of the shell as it revolves. The combustion box and vertical uptake complete perfectly the combustion of any sulphur which is volatilized from the cylinder.

The special advantages of this burner are ease in controlling composition of gas, low cost of upkeep and

1 Paper presented at the Eighth International Congress of Applied Chemistry, New York, September, 1912. 
freedom from losses. Once in about two months it is necessary to clean out the dross which collects in the cylinder. To do this, or to prepare for a shut-down for repairs in any other part of the plant, the sulphur charge is allowed to burn out completely. Any residue in the cylinder is then easily removed by a hoe. Starting the burner after cleaning, or even when it is cold, is a simple operation and no losses occur.

At the exit from the dust catcher the gas has cooled to a temperature of about $230^{\circ} \mathrm{C}$. At this point it enters the purifying system, consisting first of 250 linear feet of horizontal lead pipe arranged in tiers in a wooden rack. All gas passes through this total length of pipe. This pipe is cooled by a water spray, and here is deposited a small quantity of weak sulphuric acid formed in burning the sulphur. The acid deposited is, however, slight in comparison with the amount collected at the same point when pyrites was burned. The lead pipe connects with a large leadlined box containing coke and here a further deposit of weak acid is obtained. Up to this point also is formed a slight deposit of carbonaceous matter from the asphaltic material which Louisiana brimstone always carries in small quantities.

From the coke box the gas passes to two wet scrubbers in tandem. Each scrubber outfit consists of a vertical lead cylinder with conical top, about $4 \mathrm{ft}$. high, a lead pot provided with lead cooling coils for water, and an air lift for circulating constantly a stream of sulphuric acid from the pot to the scrubber. The scrubber is divided horizontally by perforated diaphragms. The acid washes and dries the gas thoroughly and flows out through trapped pipes in a weakened condition to the pot. A pot holds $2500 \mathrm{lbs}$. of acid and is constantly strengthened to a gravity of r.75 by the addition of strong acid. The excess acid formed at this point is collected in an egg and can be forced by air pressure to the weak acid supply used in the absorbing system. The air lift was designed by one of us (Patterson) to replace the ordinary bubbler formerly used. Only $5 \mathrm{lbs}$. air pressure is used, raising 8o lbs. of acid per minute, and the top of the lift is gas-tight, the air being piped to the gas system preventing any loss of $\mathrm{SO}_{2}$ at this point.

From the scrubbers the gas passes to a second leadlined coke box exactly like the first one and thence to a pair of dry filters in parallel. Each dry filter consists of three superimposed lead-lined iron trays luted together. Each tray contains a mat of dry asbestos fiber supporting a quantity of slag wool. A reserve set of these filters is kept ready for use as they require to be renewed about once in four weeks. The entire charge for two filters is $30 \mathrm{lbs}$. of asbestos and $400 \mathrm{lbs}$. of slag wool. The dry filters complete the purification process and the gas is then carried into the main building. Throughout the purification process the gas comes in contact with no other metal than lead, but beyond this point either cast iron or wrought iron is used entirely.

Within the house, the gas first passes through a positive pressure blower, by regulating the speed of which the composition of the entrance gas is con- trolled, and the movement of gas through the whole system is completed. Manometers on either side of this blower show a suction of I. $5^{\prime \prime}$ of mercury and a pressure of $0.75^{\prime \prime}$ of mercury. Just forward of the blower is the sampling pipe where the composition of entrance gas is tested by the usual iodine solution.

The next step in the process is the conversion system which includes a preheater and converter. The preheater is a series of vertical iron $U$ pipes and headers housed in a furnace heated by soft coal to give to the gas an initial temperature of $380^{\circ} \mathrm{C}$, this being required for proper catalytic action by the contact mass.

The converter is placed close to the preheater and is a vertical cast iron cylinder $6 \mathrm{ft}$. in diameter and $8^{\mathrm{r}} / 2 \mathrm{ft}$. high, composed of 5 horizontal sections. Each section contains a wire mesh tray for supporting the contact mass and a baffle to properly spread the gas. The contact mass is anhydrous magnesium sulphate carrying two-tenths of one per cent. metallic platinum in finely divided condition. A total quantity of 5900 lbs. of mass which is in coarse granules is spread on the trays to a depth of $14-16$ inches, leaving a space of about 6 inches between mass sections. The gas enters the bottom of the converter and leaves at the top, pyrometer tubes being provided to read the gas temperature before entrance and in each section. From the converter the gas passes through $\mathrm{r} 80$ feet of iron pipe to the absorber. This pipe is air-cooled in order that the temperature of the gas may be sufficiently low for good absorption.

The absorbing system consists of a tower absorber, an acid-cooling pipe, a weak acid mixer and reservoir, a head tank for strong acid, an acid pump, and collecting tank. The tower is a vertical cast iron cylinder $15 / 2 \mathrm{ft}$. high resting on a cast iron base, the top being covered by a perforated plate from the center of which rises the exit pipe for waste gases. The tower is lined with acid tile and packed with quartz rock. The gas enters on one side near the bottom. A constant stream of acid is supplied by the pump to the top plate, percolates through the mass of quartz and passes out at the bottom of the tower to the cooling pipe. This is a horizontal water-cooled $U$ pipe, one leg of which carries an overflow pipe connecting with the pump and the collector. The acid supplied to the top of the tower is kept at a temperature of $70^{\circ} \mathrm{C}$. and has a strength of 99.5 per cent. $\mathrm{H}_{2} \mathrm{SO}_{4}$. The strength of the acid leaving the bottom of the tower is reduced by the constant addition of a small stream of 75 per cent. $\mathrm{H}_{2} \mathrm{SO}_{4}$ just before it enters the cooler.

The reservoir of this weak acid, the mixer and strong acid head tank are mounted on a platform in the center of the building at a sufficient elevation for the acid to flow by gravity. The reservoir is an open leadlined box holding rooo gallons. The mixer is a lead pot provided with lead coils for cooling water and a special mixing pipe designed by one of us (Cheney) in which water and strong acid are brought in contact. The mixing pipe consists of two heavy $3 / 4$ " lead pipes set at an angle of $30^{\circ}$ and held together by a heavy lead sheath burned onto a short length of $\mathrm{I}^{\mathrm{I}} /{ }_{2}^{\prime \prime}$ lead pipe. One of the $3 / 4$ " pipes carries strong acid from 
the head tank, and the other ordinary cold water from the mains. 'The $\mathrm{I}^{\mathrm{r}} / \mathrm{z}^{\prime \prime}$ pipe serves to carry the hot mixture to the pot without spatter. This type has the advantage of minimum repair and mixes about 5000 lbs. of 75 per cent. acid per hour. The head tank has a capacity of $18,000 \mathrm{lbs}$. of strong acid.

The product of the plant passes through a scale tank and is delivered to the nitric acid plant where in winter weather it is mixed with 2 per cent. of nitric acid to prevent freezing. The entire product can be delivered as 99.5 per cent. $\mathrm{H}_{2} \mathrm{SO}_{4}$, but for use in making nitric acid a portion of it is reduced to 94 per cent. $\mathrm{H}_{2} \mathrm{SO}_{4}$.

This being a government plant the hours of labor for any one shift of men can not exceed eight. The plant is run continuously with three shifts and in addition to the men directly employed in the operation of the plant there is a superintendent who devotes about half of his time to it.

The successful operation of a contact plant, of course, depends largely upon the efficiency of the contact mass. This efficiency is easily influenced by arsenic in the raw materials. Should arseniuretted hydrogen be present in the gas entering the converter, arsenic is deposited on the platinum and is said to "poison" it. The result of "poisoning" is immediately noticeable in the temperature produced by the catalytic action and in the quantity of $\mathrm{SO}_{2}$ unconverted. Fortunately, this effect may in part be counteracted by raising the temperature of the gases entering the converter, and for this reason hardly any two plants burning pyrites will be found using the same initial temperature. In different plants we have noted temperatures of entrance gas varying from $420^{\circ} \mathrm{C}$. to $480^{\circ} \mathrm{C}$. The catalytic properties of "poisoned" mass may be improved by sprinkling it with aqua regia and expelling the arsenic by the heat of the converter, or they may be entirely restored by heating the mass in a furnace after sprinkling with aqua regia.

Another factor in conversion is the quantity of $\mathrm{SO}_{2}$ contained in the gas entering the converter. With pyrites it is customary to use an entrance gas containing not over 5.5 per cent. $\mathrm{SO}_{2}$ with mass in good condition. When "poisoning" has occurred, this percentage must be reduced to obtain good conversion.

In this plant, using Louisiana brimstone for eighteen months, we have had no indications of "poisoning" and have not opened the converter. The temperature of gas entering the converter is kept constantly at $380^{\circ} \mathrm{C}$. and conversions are regularly $95^{-95}-5$ per cent. This low temperature means a decided saving in coal, and wear and tear on the preheater. During six months the average consumption of coal has been 2 I. 8 lbs. per 100 lbs. of $\mathrm{SO}_{3}$ made. We believe this to be a figure decidedly less than in any Schroeder plant burning pyrites. An entrance gas of $6.5-7$ per cent. $\mathrm{SO}_{2}$ is regularly used. During six months under the above conditions, the average make has been a little more than 6 tons of acid a day, and the average yield on sulphur fed to the burner 93.36 per cent. The plant can make a maximum quantity of 8 tons with a yield of 90 per cent. Comparison of cost sheets shows that by changing raw materials from pyrites to brimstone, we have reduced cost of manufacture nearly two dollars per ton of 98 per cent. acid; that this reduction is due in part to minimizing losses from shut-downs for repairs, in part to increased yields and in part to saving in coal and cost of upkeep.

\section{U. S. Naval Proving Ground,}

INDIAN HEAD, MD.

\section{SMELTER SMOKE CONSERVATION.}

\section{By George C. Westby.}

Received August 21, 1912.

The question of smelter smoke treatment is one of commercial metallurgy, and the application of a panacea a question of dollars and cents.

There have been many plans devised for quieting the complaints of injured agriculturists and others to whom smelter smoke seems all that is evil, but too often the proposed plan has been merely mitigatory, or has neglected provision for a material return on the investment in the plant. In other cases the process is rendered inapplicable on account of limited demand for the output whose production and sale is the vital commercial feature.

Of the methods projected for treating smelter smoke in an economic way, this article is limited to consideration of methods with which the writer has experimented.

The first of these was developed during $1902-1903$ and consisted of a process for producing liquid $\mathrm{SO}_{2}$ from the smoke, utilizing the heat of the smoke by means of economizers and air heaters. The $\mathrm{SO}_{2}$ was to be liquefied by an ice or refrigerating machine, with the crystallohydrate of $\mathrm{SO}_{2}$ as an intermediary product.

Aside from the mechanical difficulties incident to the arrangements for removing the flue dust, the crucial objection advanced against the process was the lack of a market for the liquid gas as produced at the rate of thousands of tons per day. The suggestion that it could be used as a refrigerant in place of ice in freight cars, and in the small ice boxes of private homes, seemed inadequate in face of the fact, that the market was both problematical and undeveloped while awaiting the expenditure of some millions of dollars in providing the necessary equipment. ${ }^{\prime}$

During the course of further work in connection with the smoke problem, the idea suggested itself that the sulphurous gases of the smoke might be bound with the bases of slag and thus reduced to a more controllable form. Experiment demonstrated that the idea might be practically applied, and also suggested the general method of smoke treatment which consists in the neutralization of acid fumes on slag, and ensuing precipitation of the toxic oxides in ponds or other limited areas on the earth, chiefly as harmless and insoluble compounds with iron and other bases of the slag. As developed, the process also involved the recovery of values carried by slag and flue dust.

1 This phase of smoke eradication method was independently educed by Dr. Carpenter, of Denver. 